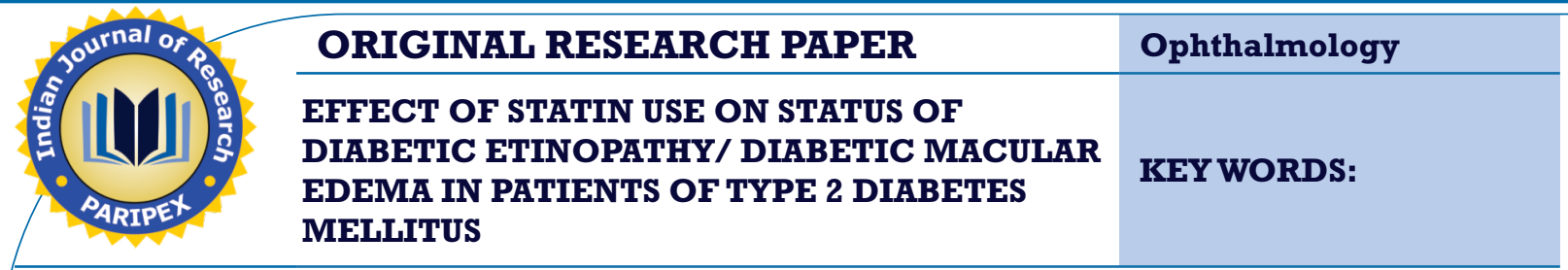

\section{Dr. Lolkesh}

Kumar Singh

\section{Dr. Alka Gupta}

\section{Dr. Jigyasa}

Srivastava
Assistant Professor,llrm, Medical College Meerut.

Professor,LLRM, Medical College Meerut.

MS Ophthalmology,Junior Resident,LLRM Medical College Meerut.

\title{
AIM:
}

Effect of statin use on status of diabetic retinopathy /diabetic macular edema in patients of type 2 diabetes mellitus

Check the lipid profile and detail fundus examination of all patients included in study.

Effect of lipid lowering agents (statin) on Diabetic retinopathy.

Asses the changes in fundus of DME patients after giving statin.

MATERIALS AND METHODS:-

A prospective study was conducted in the OPD of upgraded department of ophthalmology at LLRM Medical College, Meerut over the duration of from July 2019 to June 2020.

The proposed study was in association of status use and hyper triglyceridemia with diabetes macular edema in patients with type-2 diabetes and diabetic retinopathy. Clearance from institution ethics committee was obtained before the study was started.

An informed consent was obtained from all the patients before including them in to the study.

A total of 86 patients were divided in to two equal groups randomly

RESULTS:-

A prospective study was conducted in the OPD of upgraded department of ophthalmology at LLRM Medical College, Meerut over the duration of from July 2019 to June 2020 and sample size of patients taken was 86

About $70.9 \%$ of the patients in this study were males and $29.1 \%$ were females.

About $26.7 \%$ of the study subjects in this study had diabetes mellitus since $16-20$ years, $25.6 \%$ since more than 20 years and $20.9 \%$ since $11-15$ years.

During the baseline the CSME in left eye was present in $24.4 \%$ of the cases and during follow up, the CSME was present in $10.5 \%$ of the cases

At the time of baseline, about $64 \%$ of the patients had no CSME in right eye and $36 \%$ had CSME. At the time of follow up $87.2 \%$ of the cases had no CSME and $12.8 \%$ had CSME.

In mild NPDR during follow up, 44.2\% had mild NPDR, 24.4\% had moderate NPDR and $8.1 \%$ had severe NPDR at baseline.

About $17.4 \%$ of the patients who had moderate NPDR at baseline also had moderate NPDR during follow up visits in left eye.

Among all the patients with mild NPDR during follow up, 54.7\% had mild NPDR, $22.1 \%$ had moderate NPDR and $10.5 \%$ had severe NPDR during baseline. About $12.8 \%$ who had moderate NPDR during baseline also had moderate NPDR during follow up in right eye

Mean cholesterol level during baseline was $154.13 \mathrm{mg} / \mathrm{dl}$ and during follow up was $138.12 \mathrm{mg} / \mathrm{dl}$ which was statistically significant $(\mathrm{p}=0.000)$.

The mean triglyceride level during the baseline was $178.37 \mathrm{mg} / \mathrm{dl}$ and during follow up was $156 \mathrm{mg} / \mathrm{dl}$ which was statistically significant between the two groups $(\mathrm{p}=0.000)$.

Mean LDL cholesterol level during the baseline was $94.99 \mathrm{mg} / \mathrm{dl}$ and during follow up was $61.24 \mathrm{mg} / \mathrm{dl}$ which was statistically significant between baseline and follow up $(p=0.000)$.

This study had shown improvement of visual acuity, decrease in macular edema and progression of diabetic retinopathy. The study also revealed that ,the statins are effective in decreasing the total cholesterol, LDL cholesterol, and triglycerides.

\section{CONCLUSION:-}

This study had shown improvement of visual acuity, decrease in macular edema and progression of diabetic retinopathy in patients whom statins was given

The study also revealed that, the statins are effective in decreasing the total cholesterol(mean value during baseline was $154.13 \mathrm{mg} / \mathrm{dl}$ which reduces to $138.12 \mathrm{mg} / \mathrm{dl}$ during follow up), LDL cholesterol (mean value reduces from $94.99 \mathrm{mg} / \mathrm{dl}$ during baseline to $61.24 \mathrm{mg} / \mathrm{dl}$ during follow up)and triglycerides (mean value during baseline $178.37 \mathrm{mg} / \mathrm{dl}$ to 156 $\mathrm{mg} / \mathrm{dl}$ during follow up).as given.

\section{INTRODUCTION:}

Diabetic retinopathy is the most frequently occurring chronic micro vascular complication in patients with diabetes resulting from hyperglycemia, glucose related hyperosmolarity, and DME is a leading cause of severe vision loss in patients with diabetic retinopathy

Progression of DR and DME is known to be associated with duration of diabetes and hypertension, dyslipidemia is also a risk factor too.

Duration of diabetes is the most important risk factor. In patients diagnosed with diabetes before age of $30 \mathrm{yr}$, the incidence of
$\mathrm{DR}$ after $10 \mathrm{yr}$ is $50 \%$, and after $30 \mathrm{yr}$ is $90 \%$. DR rarely develops within 5 yrs of the onset of diabetes or before puberty, but about $5 \%$ of type 2 diabetes have DR at presentation.

Some reports have shown that, intensive control of lipids in patients with diabetes can also delay the progression of DR and suggested that two types of lipid lowering agents including fibrates and statins can be used to prevent the progression of DR.

\section{AIM-}

The aim of study was to see the effect of statin use on status of DR and DME in type $2 \mathrm{DM}$ patients. 


\section{MATERIAL AND METHODS}

A prospective study was conducted in the OPD of upgraded department of ophthalmology at LLRM Medical College, Meerut over the duration of from July 2019 to June 2020.

Keeping in mind the maximum prevalence of DR in type 2DM in north india $34.06 \%$ with $10 \%$ absolute precision $95 \%$ CI the following formula is use to calculate the sample size.

\section{SAIMPLE SIZE CALCULATION}

$\mathrm{n}=(1.96)^{2} \mathrm{pq} / \mathrm{d}^{2}$

where, $\mathrm{n}=$ sample size, $\mathrm{d}=$ absolute precision, $\mathrm{p}=$ prevalence $\mathrm{q}=(1-\mathrm{p})$

$$
\begin{gathered}
\frac{3.84 \times 0.3406 \times 0.6594}{(0.1)^{2}} \\
\frac{0.8624}{.01}=86
\end{gathered}
$$

We enrolled the patients attending the OPD of department of medicine and ophthalmology during my study.

\section{INCLUSION CRITERIA}

- Type-2 DM patient with DR with or without DME.

- Sex-Either sex.

\section{EXCLUSION CRITERIA}

- NoDR.

- Use of any other lipid lowering agent other than statins.

- DR patients requiring any other treatment like anti -VEGF ,laser ,or any surgical treatment.

- Follow of less than 1 year.

- Hypertension retinopathy patient.

- Sickle cell disease patient.

- Mature cataract \& hazy media.

- Vitrectomy.

- Other retinal diseases.

\section{RESULT AND OBSERVATION-}

Table 6. Distribution of the study group according to CSME (RE)

\begin{tabular}{|c|c|c|}
\hline CSME (RE) & Baseline n (\%) & Follow up n (\%) \\
\hline Absent & $55(64.0)$ & $75(87.2)$ \\
\hline Present & $31(36.0)$ & $11(12.8)$ \\
\hline Total & $86(100)$ & $86(100)$ \\
\hline
\end{tabular}

$\chi^{2}$ Value $=0.484 \quad \mathrm{df}=1 \quad$ p value, sig $=0.001$, Sig

Table 5. Distribution of the study group according to CSME (LE)

\begin{tabular}{|c|c|c|}
\hline CSME (LE) & Baseline n (\%) & Follow up n (\%) \\
\hline Absent & $65(75.6)$ & $77(89.5)$ \\
\hline Present & $21(24.4)$ & $9(10.5)$ \\
\hline Total & $86(100)$ & $86(100)$ \\
\hline$\chi^{2}$ Value=9.721 $\quad$ df=1 p value, sig=0.002, Sig
\end{tabular}

Table 7. Distribution of the study group according to Diabetic retinopathy (LE)

\begin{tabular}{|c|c|c|c|}
\hline DR (LE) & $\begin{array}{c}\text { Mild NPDR } \\
\text { n (\%) }\end{array}$ & $\begin{array}{c}\text { Moderate } \\
\text { NPDR n (\%) }\end{array}$ & $\begin{array}{c}\text { Severe NPDR } \\
\text { n (\%) }\end{array}$ \\
\hline Mild NPDR & $38(44.2)$ & 0 & 0 \\
\hline Moderate NPDR & $21(24.4)$ & $15(17.4)$ & 0 \\
\hline Severe NPDR & $7(8.1)$ & $4(4.7)$ & $1(1.2)$ \\
\hline Total & $66(76.7)$ & $19(22.1)$ & $1(1.2)$ \\
\hline \\
$\chi^{2}$ Value=32.0 df=3 p value, sig=0.000, Sig
\end{tabular}

Table 8. Distribution of the study group according to Diabetic retinopathy (RE)

\begin{tabular}{|c|c|c|c|}
\hline DR (RE) & $\begin{array}{c}\text { Mild NPDR } \\
\text { n (\%) }\end{array}$ & $\begin{array}{c}\text { Moderate } \\
\text { NPDR n (\%) }\end{array}$ & $\begin{array}{c}\text { Severe } \\
\text { NPDR n (\%) }\end{array}$ \\
\hline
\end{tabular}

\begin{tabular}{|c|c|c|c|}
\hline Mild NPDR & $47(54.7)$ & 0 & 0 \\
\hline Moderate NPDR & $19(22.1)$ & $11(12.8)$ & 0 \\
\hline Severe NPDR & $9(10.5)$ & 0 & 0 \\
\hline Total & $75(87.2)$ & $11(22.1)$ & 0 \\
\hline
\end{tabular}

$\chi^{2}$ Value $=28.0 \quad \mathrm{df}=3 \quad \mathrm{p}$ value, sig $=0.000$, Sig

\section{DISCUSSION}

Diabetes mellitus is a complex metabolic disease and carries high mortality and morbidity with variety of complications which are known to worsen if left untreated. ${ }^{1,2}$

Diabetic retinopathy is the most frequently occurring chronic micro vascular complication in patients with diabetes resulting from hyperglycemia, glucose related hyperosmolarity, and DME is a leading cause of severe vision loss in patients with diabetic retinopathy. ${ }^{3}$ Diabetic retinopathy also results due to elevated blood lipid levels particularly cholesterol and low density lipoprotein (LDL). ${ }^{7,8,910}$

Some reports have shown that, intensive control of lipids in patients with diabetes can also delay the progression of DR and suggested that two types of lipid lowering agents including fibrates and statins can be used to prevent the progression of DR. ${ }^{11,12}$

But the results of many studies have not demonstrated beneficial effects of lipid lowering agents such as statins. Hence it was decided to take up this study to ascertain effect of statin use on status of diabetic retinopathy and diabetic macular edema.

A prospective study was conducted in the OPD of upgraded department of ophthalmology at LLRM Medical College, Meerut over the duration of from July 2019 to June 2020. The proposed study was in association of statin use and hyper triglyceridemia with diabetes macular edema in patients with type-2 diabetes and diabetic retinopathy. A total of 86 patients constituted the sample size. Age group

This study had shown that, majority of the patients were aged more than 40 years. In a study by Kung et al (2019), the mean age of patients in statin group was 61.5 years and no statin group was 61.0 years. ${ }^{13}$ In a study by Chung et al (2017), the mean age in statin group was 58.1 years and 52.3 years in the no statin group. ${ }^{14}$

\section{Sex}

About $70.9 \%$ of the patients in this study were males and $29.1 \%$ were females in this study. In a study by Chung et al (2017), males were more in statin group and females in no stating group. ${ }^{14}$

\section{Duration of Diabetes mellitus}

About $26.7 \%$ of the study subjects in this study had diabetes mellitus since $16-20$ years, $25.6 \%$ since more than 20 years and $20.9 \%$ since $11-15$ years. The mean duration of the diabetes in Chung et al (2017) was 12.4 years in statin group and 8.6 years in no statin group. ${ }^{14}$

\section{Visual acuity}

The Logmar visual acuity at the baseline was 3 and 2.05 during the follow up in the right eye. At the time of baseline, the Logmar vision for the left eye was 2.95 and 2.17 during the time of follow up which was statistically significant $(p=0.000$ in both eyes) between the two groups. In a study by Shi et al (2018), there no significant difference in worsening of visual acuity between the lipid lowering drugs and the placebo groups. ${ }^{15}$ In a study by Sen et al (2002), VA improved in four patients using simvastatin, and worsening of VA occurred in seven patients in the placebo group. ${ }^{16}$

\section{CSME}

During the baseline the CSME in Left eye was present in $24.4 \%$ of the cases and during follow up, the CSME was 
present in $10.5 \%$ of the cases. This difference was statistically significant between the baseline and follow up $(p=0.016)$. At the time of baseline, about $64 \%$ of the patients had no CSME in Right eye and $36 \%$ had CSME. At the time of follow up $87.2 \%$ of the cases had no CSME and $12.8 \%$ had CSME in Right eye. In a study by Kang et al (2019), in the statin group macular edema was significantly lower than the no statin group. ${ }^{51}$ In a study by Chung et al (2017), macular edema was present in $23 \%$ of the statin group and $48 \%$ of the no statin group had diabetic macular edema. ${ }^{14}$

\section{Severity of Diabetic retinopathy}

In mild NPDR during follow up, $44.2 \%$ had mild NPDR, $24.4 \%$ had moderate NPDR and $8.1 \%$ had severe NPDR at baseline. About $17.4 \%$ of the patients who had moderate NPDR at baseline also had moderate NPDR during follow up visits in left eye. Among all the patients with mild NPDR during follow up, $54.7 \%$ had mild NPDR, $22.1 \%$ had moderate NPDR and $10.5 \%$ had severe NPDR during baseline in right eye. About $12.8 \%$ who had moderate NPDR during baseline also had moderate NPDR during follow up in right eye. Kang et al (2019) had shown that, about $10.6 \%$ in the statin group and $12.0 \%$ in the no statin group developed diabetic retinopathy. The patients in the statin group had a significantly lower rate of diabetic retinopathy, non proliferative \& proliferative diabetic retinopathy, vitreous hemorrhage and tractional retinal detatchment. ${ }^{13}$ A study by Shi et al (2018) had shown that, the lipid lowering drugs were associated with reduced risk in DR progression. In a study by Chung et al (2017), use of statins by patients with type 2 diabetes and pre-existing $D R$ did not increase the risk of DR Progression. Al - Janabi et al (2018) reported that, simvastatin $20 \mathrm{mg}$ delayed the progression of DR compared with placebo treated controls. ${ }^{17}$

\section{Total Cholesterol}

Mean cholesterol level during baseline was $154.13 \mathrm{mg} / \mathrm{dl}$ and during follow up was $138.12 \mathrm{mg} / \mathrm{dl}$ which was statistically significant $(p=0.000)$. In a study by Chung et al (2018), the mean total cholesterol was $4.4 \mathrm{mmol} / \mathrm{L}$ in statin group and 4.4 $\mathrm{mmol} / \mathrm{L}$ in no statin group. ${ }^{14}$ In a study by Sen et al (2002), total cholesterol decreased in simvastatin group. ${ }^{16}$

\section{Triglyceride levels}

The mean triglyceride level during the baseline was 178.37 $\mathrm{mg} / \mathrm{dl}$ and during follow up was $156 \mathrm{mg} / \mathrm{dl}$ which was statistically significant $(p=0.000)$ between the two groups. Mean triglyceride level in statin group was $1.9 \mathrm{mmol} / \mathrm{L}$ and $2.1 \mathrm{mmol} / \mathrm{L}$ in no statin group in a study by Chung et al (2018). ${ }^{16}$

\section{LDL cholesterol levels}

Mean LDL cholesterol level during the baseline was 94.99 $\mathrm{mg} / \mathrm{dl}$ and during follow up was $61.24 \mathrm{mg} / \mathrm{dl}$ which was statistically significant $(p=0.000)$ between baseline and follow up. In a study by Chung et al (2017), the level of LDL cholesterol was $2.1 \mathrm{mmol} / \mathrm{L}$ in statin group and $3.0 \mathrm{mmol} / \mathrm{L}$ in no statin group. ${ }^{53}$ In a study by Sen et al, low density lipoprotein decreased in simvastatin group (2002). ${ }^{16}$

\section{CONCLUSION-}

This study had shown improvement of visual acuity, decrease in macular edema and progression of diabetic retinopathy.

The study also revealed that ,the statins are effective in decreasing the total cholesterol, LDL cholesterol, and triglycerides.-This study had shown improvement of visual acuity, decrease in macular edema and progression of diabetic retinopathy.

The study also revealed that, the statins are effective in decreasing the total cholesterol, LDL cholesterol, and triglycerides.

\section{SUMMARY-}

- A prospective study was conducted in the OPD of upgraded department +of ophthalmology at LLRM Medical College, Meerut over the duration of from July 2019 to June 2020 and sample size of patients taken was 86 .

- This study had shown that, majority of the patients were aged more than 40 years.

- About $70.9 \%$ of the patients in this study were males and $29.1 \%$ were females.

- About $26.7 \%$ of the study subjects in this study had diabetes mellitus since $16-20$ years, $25.6 \%$ since more than 20 years and $20.9 \%$ since $11-15$ years.

- The Logmar visual acuity at the baseline was 3 and 2.05 during the follow up in the right eye.

- At the time of baseline, the Logmar vision for the left eye was 2.95 and 2.17 during the time of follow up which was statistically significant $(p=0.000$ in both eyes) between the two groups.

- During the baseline the CSME in left eye was present in $24.4 \%$ of the cases and during follow up, the CSME was present in $10.5 \%$ of the cases

- At the time of baseline, about $64 \%$ of the patients had no CSME in right eye and $36 \%$ had CSME. At the time of follow up $87.2 \%$ of the cases had no CSME and $12.8 \%$ had CSME.

- In mild NPDR during follow up, $44.2 \%$ had mild NPDR, $24.4 \%$ had moderate NPDR and $8.1 \%$ had severe NPDR at baseline. About $17.4 \%$ of the patients who had moderate NPDR at baseline also had moderate NPDR during follow up visits in left eye.

- Among all the patients with mild NPDR during follow up, $54.7 \%$ had mild NPDR, $22.1 \%$ had moderate NPDR and $10.5 \%$ had severe NPDR during baseline. About $12.8 \%$ who had moderate NPDR during baseline also had moderate NPDR during follow up in right eye.

- Mean cholesterol level during baseline was $154.13 \mathrm{mg} / \mathrm{dl}$ and during follow up was $138.12 \mathrm{mg} / \mathrm{dl}$ which was statistically significant $(\mathrm{p}=0.000)$.

- The mean triglyceride level during the baseline was $178.37 \mathrm{mg} / \mathrm{dl}$ and during follow up was $156 \mathrm{mg} / \mathrm{dl}$ which was statistically significant between the two groups $(\mathrm{p}=0.000)$.

- Mean LDL cholesterol level during the baseline was 94.99 $\mathrm{mg} / \mathrm{dl}$ and during follow up was $61.24 \mathrm{mg} / \mathrm{dl}$ which was statistically significant between baseline and follow up $(p=0.000)$.

\section{SUMMMARY-}

- A prospective study was conducted in the OPD of upgraded department +of ophthalmology at LLRM Medical College, Meerut over the duration of from July 2019 to June 2020 and sample size of patients taken was 86 .

- This study had shown that, majority of the patients were aged more than 40 years.

- About $70.9 \%$ of the patients in this study were males and $29.1 \%$ were females.

- About $26.7 \%$ of the study subjects in this study had diabetes mellitus since $16-20$ years, $25.6 \%$ since more than 20 years and $20.9 \%$ since $11-15$ years.

- The Logmar visual acuity at the baseline was 3 and 2.05 during the follow up in the right eye.

- At the time of baseline, the Logmar vision for the left eye was 2.95 and 2.17 during the time of follow up which was statistically significant $(p=0.000$ in both eyes) between the two groups.

- During the baseline the CSME in left eye was present in $24.4 \%$ of the cases and during follow up, the CSME was present in $10.5 \%$ of the cases

- At the time of baseline, about $64 \%$ of the patients had no CSME in right eye and $36 \%$ had CSME. At the time of follow up $87.2 \%$ of the cases had no CSME and $12.8 \%$ had CSME.

- In mild NPDR during follow up, $44.2 \%$ had mild NPDR, $24.4 \%$ had moderate NPDR and $8.1 \%$ had severe NPDR at baseline. About $17.4 \%$ of the patients who had moderate NPDR at baseline also had moderate NPDR during follow up visits in left eye.

- Among all the patients with mild NPDR during follow up, 
$54.7 \%$ had mild NPDR, $22.1 \%$ had moderate NPDR and $10.5 \%$ had severe NPDR during baseline. About $12.8 \%$ who had moderate NPDR during baseline also had moderate NPDR during follow up in right eye.

- Mean cholesterol level during baseline was $154.13 \mathrm{mg} / \mathrm{dl}$ and during follow up was $138.12 \mathrm{mg} / \mathrm{dl}$ which was statistically significant $(p=0.000)$.

- The mean triglyceride level during the baseline was $178.37 \mathrm{mg} / \mathrm{dl}$ and during follow up was $156 \mathrm{mg} / \mathrm{dl}$ which was statistically significant between the two groups $(\mathrm{p}=0.000)$.

- Mean LDL cholesterol level during the baseline was 94.99 $\mathrm{mg} / \mathrm{dl}$ and during follow up was $61.24 \mathrm{mg} / \mathrm{dl}$ which was statistically significant between baseline and follow up $(\mathrm{p}=0.000)$.

\section{REFERENCES}

1. Da silva correa ZM, Freitas AM, Marcon MM. Risk factors related to the severity of diabetic retinopathy. Arq Bras Oftalmol 2003;66(6):739-43.

2. Chiarelli F, Mohn A, Tumini S, Trotta D, Verrotti A. Screening for vascular complications in children and adolescents with type 1 diabetes mellitus. Horm Res 2002;57(suppl 1):113-116.

3. Lee R, Wong TY, Sabanayagam C. Epidemiology of diabetic retinopathy, diabetic macular edema and related vision loss. Eye Vis (Lond). 2015;2:17. Published 2015 Sep 30. doi:10.1186/s40662-015-0026-2.

4. Cheung N, Mitchell P, Wong TY. Diabetic retinopathy. Lancet. 2010; 376(9735): 124-36.

5. Bourne RR, Stevens GA, White RA, Smith JL, Flaxman SR, Price H, et al. Causes of vision loss worldwide, 1990-2010: a systematic analysis. Lancet Glob Health. 2013;1(6):e339-49.

6. Yau JW, Rogers SL, Kawasaki R, Lamoureux EL, Kowalski JW, Bek T, et al. Global prevalence and major risk factors of diabetic retinopathy. Diabetes Care. 2012;35(3):556-64.

7. Sacks FM, Hermans MP, Fioretto P, et al. Association between plasma triglycerides and high-density lipoproteincholesterol and microvascular kidney disease and retinopathy in type 2 diabetes mellitus: a global casecontrolstudy in 13 countries. Circulation 2013; 129(9):999-1008.

8. Golubovic-Arsovska M. Association of dyslipidaemia with macular oedema and hard exudates in diabetic maculopathy.Prilozi 2007;28(2):149-160.

9. Valensi P, Picard S. Lipids, lipid-lowering therapy and diabetes complications.Diabetes Metab 201 1;37(1):15-24.

10. Papavasileiou $E$, Davoudi $S$, Roohipoor $R$, Cho $H$, Kudrimoti $S$, Hancock $H$, Wilson JG, Andreoli C, Husain D, James M, Penman A, Chen CJ, Sobrin L. Association of serum lipid levels with retinal hard exudates area in African Americans with type 2 diabetes. Graefes Arch Clin Exp Ophthalmol 2017;255(3):509-517.

11. Action to Control Cardiovascular Risk in Diabetes Follow- On (ACCORDION) Eye Study Group and the Action to Control Cardiovascular Risk in Diabetes Follow-On (ACCORDION) Study Group. Persistent effects of intensive glycemic control on retinopathy in type 2 diabetes in the Action to Control Cardiovascular Risk in Diabetes (ACCORD) follow-on study. Diabetes Care 2016;39(7):1089-1100.

12. Nielsen SF,Nordestgaard BG. Statin use before diabetes diagnosis and risk of microvascular disease: a nationwide nested matched study. Lancet Diabetes Endocrinol 2014;2(11):894-9

13. Kang EY, Chen TH, Garg SJ, et al. Association of Statin Therapy With Prevention of Vision-Threatening Diabetic Retinopathy. JAMA Ophthalmol. 2019;137(4):363-371.

14. Chung YR, Park SW, Choi SY, et al. Association of statin use and hypertriglyceridemia with diabetic macular edema in patients with type 2 diabetes and diabetic retinopathy. Cardiovasc Diabetol.2017;16(1):4

15. Shi R, Zhao L, Wang F, et al. Effects of lipid-lowering agents on diabetic retinopathy: a Meta-analysis and systematic review. Int $J$ Ophthalmol. 2018;11(2):287-295

16. Sen K, Misra A, Kumar A, Pandey RM, Simvastatin retards pro, Diabetes Research and Clinical Practice: 2002: 56: 1: 1 - 11.gression of retinopathy in diabetic patients with hypercholesterolemia

17. Al-Janabi A, Lightman S, Tomkins-Netzer O. 'Statins in retinal disease'. Eye (Lond). 2018;32(5):981-991. 